\title{
Effect of Healthy Instructions on Reducing Pregnant Women's Fear of Normal Delivery and Preferences for Cesarean Delivery
}

\author{
Nahed Fikry Hassan Khedr ${ }^{1}$, Maher Shams Eldeen ${ }^{2,}$ * \\ ${ }^{1}$ Woman's Health and Midwifery Nursing, Faculty of Nursing, Mansoura University, Mansoura, Egypt \\ ${ }^{2}$ Obstetrics and Gynecology, Faculty of Medicine, Mansoura University, Mansoura, Egypt
}

Email address:

dr.nahid2020@hotmail.com (N. F. H. Khedr)

*Corresponding author

\section{To cite this article:}

Nahed Fikry Hassan Khedr, Maher Shams Eldeen. Effect of Healthy Instructions on Reducing Pregnant Women's Fear of Normal Delivery and Preferences for Cesarean Delivery. American Journal of Nursing Science. Vol. 6, No. 3, 2017, pp. 176-184. doi: 10.11648/j.ajns.20170603.15

Received: February 5, 2017; Accepted: February 25, 2017; Published: March 11, 2017

\begin{abstract}
Childbirth is physiological process that needs no intervention. Cesarean delivery should only conduct when normal delivery is contraindicated to protect mothers and infant's health. Nowadays, a Cesarean Section has become a culture for escaping pain. Therefore this study aimed to evaluate the effect of healthy instructions on reducing pregnant women's fear of normal delivery and preferences for cesarean delivery. A quasi-experimental design was used. A purposive sample of 64 pregnant women was selected and divided randomly into two equal groups, 32 in each group. The study was carried out at Antenatal clinics of Obstetrics and Gynecology Center of Mansoura City. Three tools were utilized for data collection; an interviewing questionnaire and Childbirth Attitudes, Childbirth Fear Associated Factors Questionnaires to assess degree of women's fear of normal delivery and preferences for cesarean delivery. Level of fear was assessed pre and post healthy instructions. The study findings revealed that both groups were significantly different regarding the fear of normal delivery after intervention. It was obvious that before intervention more than half of both groups had preference for Cesarean Section while after intervention, vaginal delivery was the first preference of both groups. This study concluded that, healthy instructions by video and lecture educational methods were effective in making a decision on normal delivery, lessening the fear of normal labor, and diminished the incidence of elective cesarean delivery. The present study recommended to apply healthy instructions by video and lecture educational methods for raising their awareness to distinguish among normal delivery and cesarean section on large number of pregnant women for reducing fear from normal delivery and preferences for cesarean delivery.
\end{abstract}

Keywords: Healthy Instructions, Fear of Childbirth, Decision, Mode of Delivery

\section{Introduction}

Pregnancy is the most important physiological phenomenon which ends with childbirth, associated with the fear and worries [1]. Childbirth is one of the most important events in a woman's life. The entire process of pregnancy and childbirth has significant physical and emotional effects. The perceptions of labor and its experience will have an impact on woman's life at various interpersonal levels including her family and children [2, 3 and 4]. Normal delivery fear is a condition that appears clearly before giving birth, it ranges from worries to sever fear interfering with daily life activities throughout pregnancy until the approaching delivery. Also normal delivery fear is a strong reason for Cesarean birth preference [5].

Fear of pain, operative delivery, having an impaired or stillborn infant, losing control, are recognized as reasons for fear of normal delivery [6]. In addition, lacking social support and a history of abuse or difficult obstetric procedures, preexisting psychological issues, young maternal age, null-parity, can be associated factors to raise the prevalence of fear of normal delivery [7]. Normal delivery 
fear and preference for (CS) are interrelated strongly; women who fear of normal delivery are more likely to request a (CS) and are also more probably to actually have a planned Cesarean Section, in spite of the fact that Cesarean delivery has many disadvantages for both the baby and woman $[8$ and 9].

Generally, caesarean delivery is often accompanied by many complications for both the mother and the baby, including hemorrhage, infection, increased mortality, premature birth, neonatal respiratory problems, etc. [7]. World Health Organization (WHO) had the rate of Cesarean delivery to be from $10-15 \%$ of total deliveries; however, this rate varies all over the world; and indeed it is increasingly rising the Cesarean rates differ from $5-25 \%$ during the last 20 years which was different at the national and international levels as well [10]. In Egypt, the general rate of Cesarean conveyance was $47.25 \%$ in 2010. This rate is higher than different rates cited from various countries [11]. The high rate of Cesarean delivery could be credited to absence of a committed obstetric sedative staff individuals to offer epidural absence of pain inside the labor wards, the more liberal perspective of Cesarean section as an acknowledged method of delivery by junior obstetricians [12 and 13].

Cesarean delivery Preferences is usually associated with many factors like birth experience fear, anxiety, prior CS, previous harmful birth experiences, woman age, alteration in the awareness of surgical hazard, terror of labor pain. Negative feelings toward vaginal delivery concerns concerning the baby's well-being, prevention of urogenital lacerations and sexual relations dysfunction [14 and 15]. One of the most effective ways to cope with normal delivery fear is non-meditational methods including education and giving proper information to the pregnant women.

Research showed that an increase in knowledge and information influences individuals' ability to recognize key points and enhances their understanding and perception. Meanwhile, shortage of knowledge causes fear and anxiety which negatively affect decision-making [16]. An association between absenteeism of primiparous women in delivery preparation classes and pregnancy anxiety, fear of childbirth, and consequently, a request for caesarean delivery [17 and $18]$.

Women's preference and their decisions concerning their obstetric interventions is much valuable. Information is lacking on the experiences and perceptions concerning vaginal delivery compared with caesarean birth. Therefore, Preparing and offering proper information to pregnant women by applying video and lecture educational methods can assist them through bringing up their mindfulness about labor and the related mental status change to cope with labor pain which, in turn, is important to choose the best delivery method; and may reduce the unnecessary Cesarean Sections which is usually done by healthy educators. Video and lecture educational methods were used to expose differences between normal delivery and cesarean delivery used to reduce the fear of normal delivery [19].

\section{Significance of the Study}

Recently in Arab Republic of Egypt rate of elective Cesarean delivery was raised dramatically from $27.6 \%$ in 2010 to $52 \%$ in 2014 and $65 \%$ in Gharbia in 2014. These rates are more than other rates quoted from diverse parts of the world, both in the developed and developing countries.13\% of non - pregnant women are fearful enough of childbirth to delay or avoid maternity, this due to lake of knowledge, negative attitude toward normal delivery, fetal healthy, prevention of urogenital lacerations, fear of pain, change in sexual relationships and lack of experiences regarding normal delivery [17]. Small number of studies conducted to assess fear of childbirth among pregnant women with limited interventions regarding it [19]. So this study had been tried to assess pregnant women's fear of normal labor with applied intervention through mothers' education via video and lecture to prepare them psychological and mental to change women's attitude toward having a natural delivery reduce fear and unnecessary and optional (elective cesarean) and its complications.

\section{Aim of this Study}

This study aimed to evaluate the effect of healthy instructions on reducing pregnant women's fear of normal delivery and preferences for cesarean delivery.

\section{Hypothesis}

Healthy instructions by Video and lecture will have a positive effect on reducing pregnant women's fear of normal delivery and women's preferences for cesarean delivery.

\section{Subjects and Methods}

\subsection{Research Design}

A quasi-experimental research design was utilized to achieve the aim of this study. Sixty four pregnant women who admitted to Antenatal Clinics at the Obstetrics and Gynecology Center in Mansoura city.

\subsection{Setting}

The current study was conducted at Antenatal clinics of Obstetrics and Gynecology Center of Mansoura City.

\subsection{Subjects}

A purposive sample of 64 pregnant women were selected based on the inclusion criteria; nulliparous women, maternal age between 18-35 years old, gestational age of 34-36 weeks, single fetus, no indication for Cesarean delivery and uncomplicated pregnancy. Total sample divided randomly into two equal groups, 32 in each group.

Group I received healthy instructions through video.

Group 2 received healthy instructions through lecture. 


\subsection{Sample Size}

The recommended sample size for a flow rate of 75 , a confidence level of $95 \%$ and a margin of error (degree of accuracy) of 0.05 would be 32 in each group (a total of 64). Assuming that the difference in the rate of preference between the two groups of $30 \%$ would be of clinical significance at Power of the study of $80 \%$ and at $5 \%$ Level of significance. Hence, a total sample size of 64 women, 32 at each arm is recommended to investigate the effectiveness of video tape watching versus lecture method on women's preference of mode of delivery.

\subsection{Instrumentation}

Three tools were utilized to gather the required information. Tools were revised by three experts and their comments have been considered.

Tool (1) A Structured interviewing questionnaire/it was designed by researcher. This tool encompasses three parts.

Part 1. Concerned with woman's socio demographic data such as age, residence, educational level, occupation, family income, religion and antenatal classes attendance.

Part 2. Entailed number of gravidity, miscarriage and gestational weeks.

Part 3. Evaluated women's preference regarding mode of delivery, pre intervention and after intervention by two weeks and asked the women's actual mode of delivery through visit or by telephone conversation.

Tool (2) Childbirth Attitudes Questionnaires, it was adopted from [15]: This tool was utilized pre and post intervention to compare level of labor fear. It comprised of a 16-thing poll, for example, (I am truly apprehensive of conceiving an offspring) and (I have fear of excruciating work contractions). Everything was replied with a 4-point scale $(1=$ no apprehension, $2=$ mild dread, $3=$ moderate trepidation, $4=$ high dread). Whole scores extended from 16 to 64 , with higher scores mirroring a more prominent level of apprehension of labor, with 41 score speaking to low dread, 48 score speaking to direct dread and 54 score and all the more speaking to high dread.

Tool (3) Childbirth Fear Associated Factors Questionnaire, it was adopted from [13]. This tool was utilized pre and post intervention to quantify components connected with labor fear. It comprised of 3 areas to quantify the accompanying:

A. Objects of fears included 5 elements such as (labor, child's \& mother's prosperity, human services staff, family life and Cesarean section).

B. Causes of fears included 5 elements such as (negative state of mind, negative stories, disturbing data, infection and youngster related issues).

C. Manifestations of fears included 4 elements such as (stress manifestations, impact on regular daily existence, wishing to have Cesarean section and wish to maintain a strategic distance from current pregnancy \&childbirth). Each announcement was replied with a 4-point scale $(1=$ concur, 2 =agree to some degree, $3=$ differ to some degree, $4=$ don't agree). Aggregate scores went from 72 to 174, with higher scores mirroring a lower level of fear of labor.

Data collection procedures

\section{Tools Validity and Reliability}

The tools were reviewed for its contents validity from three expertise from maternity nursing department at faculty of nursing, two from Ain Shams University and one Zagazig University. Based on their recommendations the necessary modifications were made. Reliability of tools was done by using Cronbach's $\alpha$ (alpha). Reliability for tool II: Melender (2002) Questionnaire was sequenced from 0.70 to 0.91 and tool III: Childbirth Attitudes Questionnaire (CAQ) had an internal consistency reliability calculate approximately of 0.83 and hence the questionnaire was found to be highly reliable [13 and 14]. In addition Master thesis was carried out in my Country under title: Factors associated with fear of childbirth: It's effect on women's preference for elective cesarean section, Authors utilized two Tools [15] and Childbirth Attitudes Questionnaire $\}$ for collected their data [20].

\section{The Pilot Study}

A pilot study was carried out on $10 \%$ of the sample size (6 women). It aimed to test applicability and clarity of the tools, Modification was done according to the results of pilot study. The pilot sample was excluded from the study.

\section{Ethical Consideration}

An approval consent was obtained from the Research Ethics Committee at Faculty of Nursing, Mansoura University. In addition to Official Permissions was obtained from the director of Antenatal Clinics of Obstetrics and Gynecology center after an explaining the aim of the study. As well as oral consent was obtained from the women after an explaining the aim of the study, women rights to accept or refuse their participation without interference with the care provided and their data were confidential.

\section{Intervention}

Intervention were involved three phases

4. a. Assessment phase

The interviews were carried out in Antenatal Clinics. In the first interview researchers introduced their self to each participant; a full clarification about the study was done and collected baseline data about sociodemographic and obstetrical data by used tool I. Level of childbirth fear was assessed pre intervention by utilizing tool II and tool III [Childbirth Attitudes Questionnaires and Childbirth Fear Associated Factors Questionnaire] [13 and 15] and All pregnant women in both groups were asked about mode of delivery preference.

b. Implementation phase

Healthy instructions were carried out by utilized video or 
lecture. The researchers conducted one teaching session by lecture for group 1 and another one session for video group 2.

Video group

Researcher take 4-5 women every day before their entering to the examination room and they asked for entering the class room of Antenatal clinic to watch video tape for 30 minutes about normal delivery (definition, advantages, pharmacological method to reduce labor pain, natural comfort measures to relieve labor pain, preparation to delivery, mechanism of labor and Cesarean delivery and it's complications.

Lecture group

Researcher take 6-8 women every day before entering the examination room and they asked for entering the class room of Antenatal clinic for 30minutes for listening lecture about normal delivery normal delivery (definition, advantages, pharmacological method to reduce labor pain, natural comfort measures to relieve labor pain, preparation to delivery, mechanism of labor Cesarean delivery and it's complications.

c. Evaluation phase.

On time of delivery Women asked again about actual mode of delivery by telephone conversation.

Immediately after educational session and after another one and two weeks from intervention, The researchers were reassessed level of childbirth fear by utilized the previous mentioned tools asked about mode of delivery preference.in addition all participants followed till excepted date of delivery by Telephone and asked about actual mode of delivery.

\section{Statistical Design}

All factual examinations were performed utilizing SPSS for windows form 20.0 (SPSS, Chicago, IL). Ceaseless information were communicated as mean \pm standard deviation (SD), while clear cut information were communicated in number and rate. The contrasts between two gatherings was resolved utilizing autonomous specimens Student's t test for variables with persistent information or chi-square test for variables containing straight out information. Factual essentialness was set at $\mathrm{p}<0.05$.

\section{Results}

Table1. Shows socio-demographic characteristics of both groups. It is obvious that, there were no statistical significant differences regarding the socio-demographic characteristics among both groups.

Table 2. Describes obstetric history of both groups. It is clear that, there were no statistical significant differences among the both groups $(\mathrm{p}>0.05)$

Table 3. reveals that factors of childbirth fear was the highest factor associated with childbirth fear with mean \pm SD $8.4 \pm 1.3$ and cesarean section factor was the lowest factor associated with childbirth fear with mean \pm SD $1.9 \pm 0.8$. The mean total score of factors of childbirth fear was $29.1 \pm 4.5$.

Table 4. Demonstrate correlation between the sociodemographic characteristics and woman Preference of mode of delivery, it was clear that old age, highly educated women, house wives women, those from urban areas with adequate income are preferred cesarean section.

Table 5. Illustrates the pre intervention women's preference for mode of delivery and post- intervention actual mode of delivery between the two groups, it was clear that Cesarean section preference before intervention was (50\% and 56.3\%) respectively for video and lecture groups, while after intervention the actual mode of delivery were vaginal delivery by $(87.5 \% \& 65.6 \%)$ respectively for video and lecture groups.

Table 1. Frequency Distribution of General Characteristics among Studied Groups.

\begin{tabular}{|c|c|c|c|c|c|}
\hline \multirow{3}{*}{ Items } & \multicolumn{4}{|c|}{ Healthy Instructions } & \multirow{3}{*}{ Significance test- $\mathrm{P}$} \\
\hline & \multicolumn{2}{|c|}{ G1: Video(n=32) } & \multicolumn{2}{|c|}{ G2: Lecture(n=32) } & \\
\hline & No. & $\%$ & No. & $\%$ & \\
\hline \multicolumn{6}{|l|}{ Age } \\
\hline $18-23$ & 1 & 3.1 & 1 & 3.1 & \multirow[t]{3}{*}{0.676} \\
\hline $24-29$ & 15 & 46.9 & 16 & 50.0 & \\
\hline $30-35$ & 16 & 50.0 & 15 & 46.9 & \\
\hline mean $\pm S D$ & \multicolumn{2}{|c|}{$28.0 \pm 3.6$} & \multicolumn{2}{|c|}{$28.8 \pm 3.9$} & 0.411 \\
\hline \multicolumn{6}{|l|}{ Educational level } \\
\hline Unable to read or write & 1 & 3.1 & 1 & 3.1 & \multirow[t]{3}{*}{0.076} \\
\hline Primary/preparatory & 16 & 50.0 & 15 & 46.9 & \\
\hline Secondary/university & 15 & 46.9 & 16 & 50.0 & \\
\hline \multicolumn{6}{|l|}{ Occupation } \\
\hline Working & 16 & 50.0 & 12 & 37.5 & \multirow[t]{2}{*}{0.313} \\
\hline Housewife & 16 & 50.0 & 20 & 62.5 & \\
\hline \multicolumn{6}{|l|}{ Residence: } \\
\hline Rural & 16 & 50.0 & 17 & 53.1 & \multirow{2}{*}{0.616} \\
\hline Urban & 16 & 50.0 & 15 & 46.9 & \\
\hline
\end{tabular}

Age (mean $\pm S D)$ Significance test 
Table 2. Frequency Distribution of Obstetrical History among studied Groups.

\begin{tabular}{|c|c|c|c|c|c|}
\hline \multirow[t]{2}{*}{ Items } & \multicolumn{2}{|c|}{ G1: Video $(n=32)$} & \multicolumn{2}{|c|}{ G2: Lecture(n=32) } & \multirow[t]{2}{*}{ Significance test- $p$} \\
\hline & No. & $\%$ & No. & $\%$ & \\
\hline \multicolumn{6}{|l|}{ Gravida } \\
\hline Gravida 1 & 12 & 37.5 & 12 & 37.5 & \multirow[t]{3}{*}{0.803} \\
\hline Gravida 2 & 14 & 43.8 & 12 & 37.5 & \\
\hline Gravida 3 & 6 & 18.8 & 8 & 25.0 & \\
\hline \multicolumn{6}{|c|}{ Gestational age (weeks) } \\
\hline 34-35 weeks & 14 & 43.8 & 13 & 40.6 & \multirow[t]{2}{*}{0.800} \\
\hline \multicolumn{5}{|c|}{ Antenatal class attendance } & \\
\hline Yes & 26 & 81.2 & 24 & 75.0 & \multirow{2}{*}{0.545} \\
\hline No & 6 & 18.8 & 8 & 25.0 & \\
\hline
\end{tabular}

Table 3. Average Score of Factors of Childbirth Fear among pregnant women.

\begin{tabular}{llll}
\hline \multirow{2}{*}{ Items } & Score & & \\
\cline { 2 - 4 } & Minimum & Maximum & Mean \\
\hline Factor 1. Childbirth & 5 & 11 & 8.4 \\
Factor 2. Child's and Mother's Well-Being & 4 & 10 & 7.2 \\
Factor 3. Health Care Staff & 4 & 11 & 6.8 \\
Factor 4. Family Life & 3 & 8 & 1.3 \\
Factor 5. Cesarean Section & 1 & 4 & 1.4 \\
Total score & 21 & 36 & 1.8 \\
\hline
\end{tabular}

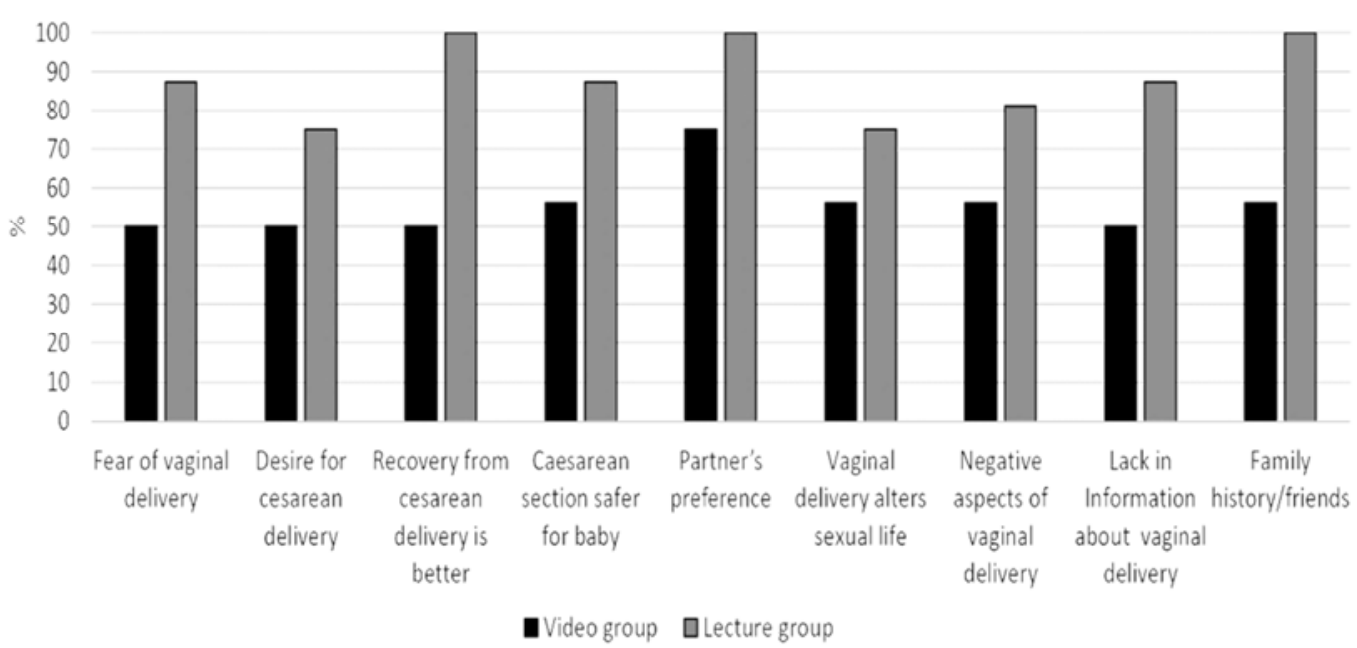

Figure 1. Reasons Reported by Women for the Preference for Cesarean Delivery among Studied Groups.

Table 4. Correlation between the Socio-demographic Characteristics and Preference of Mode of Delivery among Studied Groups.

\begin{tabular}{|c|c|c|c|c|c|c|}
\hline \multirow[b]{2}{*}{ Items } & \multicolumn{2}{|c|}{ Cesarean Delivery } & \multicolumn{2}{|c|}{ Vaginal delivery } & \multicolumn{2}{|c|}{ Chi square test } \\
\hline & No. & $\%$ & No. & $\%$ & $\mathbf{X} 2$ & $\mathbf{p}$ \\
\hline \multicolumn{7}{|l|}{ Age } \\
\hline $18-23$ & 1 & 8.3 & 2 & 3.8 & & \\
\hline $24-29$ & 1 & 8.3 & 33 & 63.5 & & \\
\hline $30-35$ & 10 & 83.3 & 17 & 32.7 & 11.923 & 0.003 \\
\hline \multicolumn{7}{|l|}{ Educational level } \\
\hline Unable to read or write & 0 & 0.0 & 7 & 14.3 & & \\
\hline Primary/preparatory & 2 & 16.7 & 22 & 44.9 & & \\
\hline Secondary/university & 10 & 83.3 & 20 & 40.8 & 6.838 & 0.032 \\
\hline \multicolumn{7}{|l|}{ Occupation } \\
\hline Working & 2 & 16.7 & 26 & 50 & & \\
\hline Housewife & 10 & 83.3 & 26 & 50 & 4.402 & 0.036 \\
\hline \multicolumn{7}{|l|}{ Religion } \\
\hline Muslim & 10 & 83.3 & 48 & 92.3 & & \\
\hline Christian & 2 & 16.7 & 4 & 7.7 & 0.924 & 0.336 \\
\hline \multicolumn{7}{|l|}{ Residence } \\
\hline Rural & 1 & 8.3 & 33 & 63.5 & & \\
\hline Urban & 11 & 91.7 & 19 & 36.5 & 11.899 & $<0.001$ \\
\hline
\end{tabular}




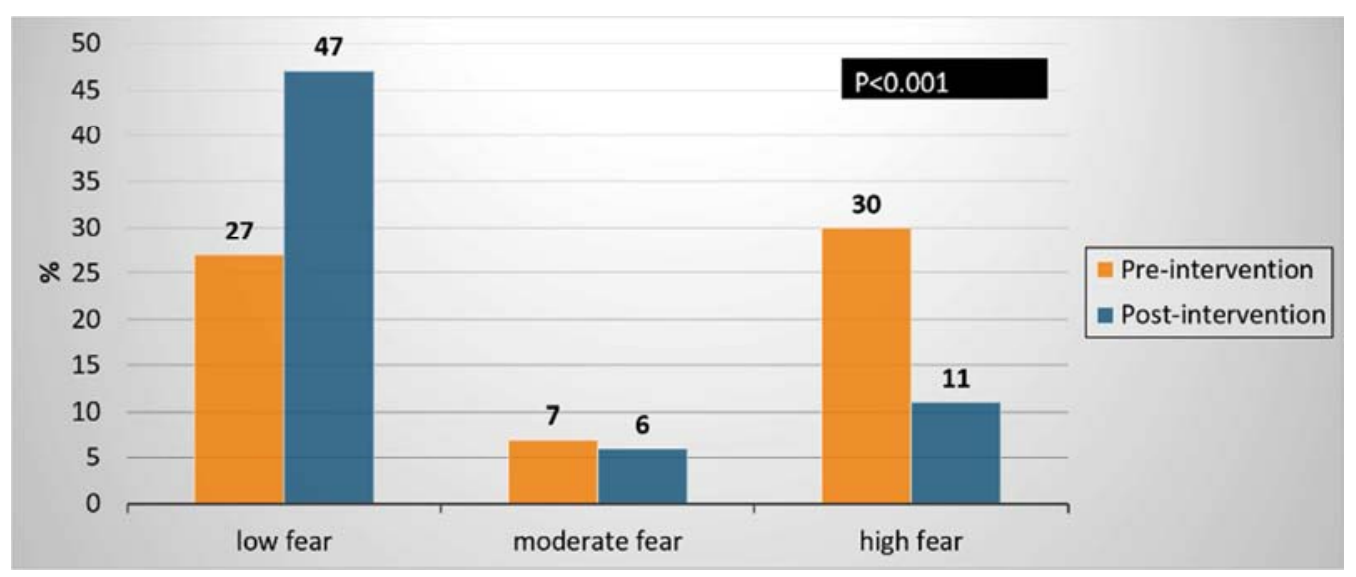

Figure 2. Comparison between Level of Childbirth Fear Pre- Intervention and Post-Intervention of among Studied Groups.

Table 5. Comparison between Pre- Intervention Women's Preference and Post-Intervention for Actual Mode of Delivery among Studied Groups.

\begin{tabular}{|c|c|c|c|c|c|c|c|c|}
\hline \multirow{3}{*}{ Mode of delivery } & \multicolumn{4}{|c|}{ Pre-Intervention (Mode of delivery Preference) } & \multicolumn{4}{|c|}{ Post- Intervention (Actual mode of delivery) } \\
\hline & \multicolumn{2}{|c|}{ G1: Video (n=32) } & \multicolumn{2}{|c|}{ G2: Lecture $(n=32)$} & \multicolumn{2}{|c|}{ G1: Video (n=32) } & \multicolumn{2}{|c|}{ G2: Lecture $(n=32)$} \\
\hline & No. & $\%$ & No. & $\%$ & No. & $\%$ & No. & $\%$ \\
\hline vaginal delivery & 16 & 50.0 & 14 & 43.7 & 28 & 87.5 & 21 & 65.6 \\
\hline Cesarean section & 16 & 50.0 & 18 & 56.3 & 4 & 12.5 & 11 & 34.4 \\
\hline $\mathrm{P}=0.616$ & & & & & $P=($ & & & \\
\hline
\end{tabular}

\section{Discussion}

The current study aimed to explore the effect of Video and lecture on reducing pregnant women's fear of normal delivery and preferences for cesarean delivery. This aim was supported by the present study hypothesis because the study results highlighted changing in women's preference from cesarean delivery to normal vaginal delivery after their acquired knowledge regarding differentiation between normal labor and cesarean delivery through video and lecture. This aim was achieved through the present study findings which revealed that almost two thirds of lecture group and more than four fifths of video group prefer normal vaginal delivery and their fear level was decreased after intervention with statistically significantly differences.

Regarding general characteristics of preferred women for cesarean delivery, the present study showed that the women were older age and high educational level women. These findings may be due to older nulliparous women prefer the benefit of getting no harm for the baby by easy surgical delivery process for him although, the risks she may face. These study findings were in agreement with [22]. studied apprehension of labor in Australia and reported that the general characteristics play a major role in the development of women's childbirth fears according to advanced age and high education [21 and 22]. Consistent with this findings, another study conducted in Norway by [23] to evaluate childbirth fears, expressed that maternal age and advanced education are associated factors for childbirth fears $[22$ and 23].

The present study finding showed that the preferred women for CS were house wives women with adequate income and from urban residence more than rural areas. This finding may be due to housewives women live in urban areas married with advanced age and may have precious baby. This finding is in agreement with another study conducted in Turkey regarding effect of education on childbirth fears, they reported that most of studied subjects were not working with moderate income, and came from urban [25].

Consistent with these findings, a descriptive study conducted by [26] studied preference after VBAC and cesarean delivery after vaginal delivery in Egypt, reported that majority of pregnant women were housewives, came from rural origin and had enough income among normal delivery after CS group.

Concerning obstetric history among pregnant women, the present study demonstrated that more than majority of preferred women to CS women did not attend antenatal classes or follow-up visits. This finding is due to a negative attitude of Egyptian pregnant women to not visit antennal clinic until there is a problem. While in the other hand a research studied experiences of fears associated with pregnancy and childbirth reported that nearly half of studied subjects go to antenatal classes [15].

Findings of the current study before intervention referred that less than one fifth of the studied groups preferred vaginal delivery and more than half preferred cesarean delivery. This study finding due to some women consider vaginal delivery as a natural method of childbirth and quicker post-delivery recovery with minimal risks when compared to CS, but a considerable portion of women prefer cesarean section because of fear of labor pain and Perineal pain after normal delivery and its influence on postpartum sexual life and because of lack of knowledge about the natural process of normal vaginal delivery and methods of pain reliever.

This result was supported by a trial involving 420 mothers conducted in South of Iran reported that more than the half of 
studied subjects preferred cesarean delivery. It proved that fear of labor pain is the strongest cause of women's preference for CS especially for nulliparous women who hadn't any previous experience [28 and 31]. In contrast, another study conducted in Northeast of Iran involving 797 pregnant women in their first pregnancy proved that almost three quarters of nulliparous women preferred normal delivery [29], and the same rate was reported by another descriptive study consisted of 840 women such study finding revealed that almost three quarters of studied subjects preferred elective cesarean section [30, 33 and 34]' this contradiction due to large sample size of contradicting studies.

Meanwhile level of fear of childbirth among studied groups by utilizing Childbirth Attitudes Questionnaires, the present study revealed that pre-intervention there were no statistical significant differences between both studied groups regarding all fear items of childbirth attitudes questionnaires and also that childbirth fear was the highest factor associated with childbirth while, cesarean section fear was the lowest factor associated with childbirth fear. These findings may be due to that all study participants were nulliparous women and had no previous experience or knowledge regarding normal childbirth. These findings are supported by a qualitative research studied fears associated with childbirth among nulliparous women in Turkey involving 19 nulliparous women reported that childbirth fear is the most common cause of preferences for CS [35].

The study achieved the hypothesis that Video and lecture will have a positive effect on reducing fear of normal delivery and on preferences for cesarean delivery. The study findings reveals that, after intervention the majority of video group and almost two thirds of lecture group delivered normally although their preferences for CS before intervention. This finding is due to the effect of increase body of knowledge and information regarding mood of delivery which influence the pregnant women ability to recognize key points and enhance best perception and decision about childbirth.

Video is more effective than a lecture because Video is a live, visual connection between two or more people for the purpose of communication. It's a simple way which provides transmission of images and text. So the women who watch video about normal delivery (definition, advantages, pharmacological and non- pharmacological method to reduce labor pain, preparation to delivery and comfort measures to relieve labor pain regarding mood of delivery) and information about cesarean delivery and it's complications) will reduce fears of labor and preferences of elective caesarean section. This study findings are supported by [32], they studied 40 requested women for primary elective CS in Egypt, reported that majority of women changed their decision to normal vaginal delivery and delivered actually by vaginal deliver after childbirth counseling [31]

Consistent with this findings, a blind clinical trial involving 67 primiparous women conducted in Iran, studied the effect of role play education on primiparous' fear of normal delivery and decision for mode of delivery, founded that majority of lecture group and all role play group choose vaginal birth to be their mood of delivery after educational interventions [36 and 37]. Non- pharmacological methods including education by lecture video are one of the most effective ways to cope with fear and providing accurate information to the pregnant women. Research showed that providing complete knowledge influences individuals' ability to enhance their healthy related decision making [36].

\section{Conclusions}

the findings of the current study revealed that, half of pregnant women preferred elective CS. women who preferred elective CS. are concerned with fear of vaginal birth, safety of the baby, old age, high level of education and housewife women, childbirth factor was the most representative factor associated with childbirth fear. After acquired healthy instructions woman's preference of mode of delivery are changed to normal delivery.

\section{Recommendations}

Based on the present study findings, the following are recommended:

1. Apply healthy instructions by video and lecture educational methods for raising women's awareness to distinguish among normal delivery and cesarean section on large number of pregnant women for reducing fear from normal delivery and preferences for cesarean delivery.

2. Providing antenatal classes regarding childbirth education including $\mathrm{x}$ husband regard the advantages of vaginal delivery and reassuring them about its importance for mother and baby.

3. Obstetricians and maternity nurses should encouraging women to express their fears about delivery, they should be good advisors.

4. Further researches are needed especially to compare the levels of fear among nulliparous and multiparous women and it should be conducted on large sample size

\section{References}

[1] Besharati, F., Hazavhei, S., Moeini, B., Beigi, A. (2011): Effect of educational interventions based on theory of planned behavior (TPB) in selecting delivery mode among pregnant women referred to rasht healthy centers. J Zanjan Univ Med Sci.; 19: 94-106.

[2] Ford, E., and Ayers, S. (2009): Stressful events and support during birth: the effect on anxiety, mood and perceived control. Journal of Anxiety Disorders. (23): 260-268.

[3] Bertucci, V., Boffo, M., Mannarini, S. (2011): Assessing the perception of the childbirth experience in italian women: a contribution to the adaptation of the childbirth perception questionnaire. Midwifery. (28): 265-274. 
[4] Helal, A., Warda, O. (2013): Rising Rates of Caesarean Delivery at Mansoura University Hospital. A Reason for Concern. Gynecol Obstet. 3: 146.

[5] Shakeri, M., Mazlomzade, S., Mohamadian, F. (2008): Factors affecting the rate of cesarean section in Zanjan maternity hospitals in J ZanjanUniv Med Sci. 2012; 20: 98-104.

[6] Zamani-Alavijeh, F., Shahry, P., Kalhory, M., Haghighizadeh, M., Sharifi-Rad, G., Khorsandi, M. (2012): Identification of factors related to elective cesarean labor: a theory-based study. SciResear J ShahedUni (Daneshvar); 19: 1-11.

[7] Mikki, N., Abu-Rmeileh, N., Wick, L., Abu-Asab, N., Bitar, S. (2009): Cesarean delivery rates, determinants and indications in Makassed Hospital, Jerusalem, 15: 868-79.

[8] Salmani, N. (2007): Assessment of the pregnant women view's in relation to affecting causes in select of delivery method in shohadakargar hospital of Yazd. J OrumiyeNurs Midwifery Fac.; 5: 156-61.

[9] Malhotra, N., and Puri, R. (2012): Donald School Manual of Practical Problems in Obestetrics. 1st ed. Replika Press, London.

[10] World Healthy Organization (2010): The Global Numbers and Costs of Additionally Needed and Unnecessary Caesarean Sections Performed per Year. Overuse as a barrier to universal coverage. pp. 30 .

[11] Zakerihamidi, M., Latifnejad, R., MerghatiKhoei, E. (2015): Vaginal Delivery vs. Cesarean Section: A Focused Ethnographic Study of Women's Perceptions in the North of Iran. Int J Community Based Nursing Midwifery. 3 (1): 39-50.

[12] Hamilton, B., Martin, J., Ventura, S. (2012): Births: preliminary data for 2011. Natl Vital Stat Rep. Oct 3; 61 (5): 1-18.

[13] Lewis, J. and Leach, J., (2006): Discussion of socio-scientific issues: The role of science knowledge. Int J Sci Educ.; 28: 1267-87.

[14] Prokop, P., Lešková, A., Kubiatko, M., Diran, C. (2007): students' knowledge of and attitudes toward biotechnology. Int J Sci Educ.; 29: 895-907.

[15] Melender, R. (2002): Experiences of fears associated with pregnancy and childbirth: A study of 329 pregnant women. Birth.; 29: 101-11.

[16] Sanavi, F., Navidian, A., Rakhshani, F., Ansari-Moghaddam, A. (2012): The effect of education on base the Theory of Planned Behavior toward normal delivery in pregnant women with intention elective cesarean. J HormozganUniv Med Sci.; 7: 531-9.

[17] El-Zanaty, F., and Ann, A. (2015): Egypt Demographic and Healthy Survey. Calverton, Maryland: Ministry of Healthy and Population [Arab Republic of Egypt], El-Zanaty and Associates, and Macro International.

[18] Kjærgaard, H., Wijma, K., Dykes, A., Alehagen, S. (2008): Fear of childbirth in obstetrically low-risk nulliparous women in Sweden and Denmark. Journal of Reproductive and Infant Psychology, 26: (4), 340-350.

[19] Hofberg, K., and Ward, M. (2007): TokophobiaTokophobia: A Profound Dread and Avoidance of Childbirth (When Pathological Fear Effects the Consultation). In Psychological Challenges in Obstetrics and Gynecology, Springer, London.
[20] Abd El-Aziz, S., Mansour, S., Hassan, N. (2017): Factors associated with fear of childbirth: It's effect on women's preference for elective cesarean section- Journal of Nursing Education and Practice 2017, Vol. 7, No. 1, pp 133-146.

[21] Spaich, S., Welzel, G., Berlit, S., et al. (2013): Mode of delivery and its influence on women's satisfaction with childbirth. Eur J ObstetGynecolReprod Biol. 170 (2): 401-6.

[22] Toohill, J., Fenwick, J., Gamble, J. and Creedy, D. (2014): Prevalence of childbirth fear in an Australian sample of pregnant women. BMC Pregnancy Childbirth, 14: (1), 275.

[23] Adams, S., Eberhard-Gran, M. and Eskild, A. (2012): Fear of childbirth and duration of labor: a study of 2206 women with intended vaginal delivery. BJOG: An International Journal of Obstetrics \& Gynaecology, 119: (10), 1238-1246.

[24] Haines, H., Rubertsson, C., Pallant, J. and Hildingsson, I. (2012): The influence of women's fear, attitudes and beliefs of childbirth on mode and experience of birth. BMC pregnancy and childbirth, 12: (1), 1-14.

[25] Kızılırmak, A. and Başer, M. (2016): The effect of education given to primigravida women on fear of childbirth. Applied Nursing Research, 29: 19-24.

[26] Fouad, S., Fathy, T. \& El-nemer, A. 2015. Women's Satisfaction and Preferences Following Vaginal Birth After Caesarean Section and Caesarean Section after Vaginal Birth. Mansoura Nursing Journal, 2 (2).

[27] Elfeshawy, M., Elmashad, M. and El-Nemer, A. (2015): Feasibility and Acceptability of Labor Companionship at Mansuora University Hospital/Egypt. ISOR Journal of Nursing and Healthy Science, 4 (5).

[28] Mohammad, A., Tabatabaei, S., Mohammad, N. and Yazdani, M. (2009): Factors influencing cesarean delivery method in Shiraz hospitals. Iran journal of nursing, 21: (56), 37-45.

[29] Gholami, A. and Salarilak, S. (2013): Why do some pregnant women prefer cesarean delivery in first pregnancy? Iranian journal of reproductive medicine, 11 (4) 301-308.

[30] Yilmaz, D., Bal, D., Beji, K. and Uludag, S. (2013): Women's Preferences of Method of Delivery and Influencing Factors. Iranian Red Crescent Medical Journal, 15 (8) 683-689.

[31] Faisal, I., Matinnia, N., Hejar, A. and Khodakarami, Z. (2014): Why do primigravidae request caesarean section in a normal pregnancy? A qualitative study in Iran. Midwifery, 30: (2), 227-233. (5).

[32] El-Nemer, A. (2015): Effect of Childbirth Counseling on Pregnant Women Requested for Cesarean Delivery. IOSR Journal of Nursing and Healthy Science (IOSR-JNHS), 4: (4), 24:29.

[33] Mohamed, L. and El Fouly, H. (2016): Women's Preferences for Mode of Delivery in Upper and Lower Egypt: A Comparative Study. IOSR Journal of Nursing and Healthy Science (IOSR-JNHS), 5: (3), 35-45.

[34] Pang, W., Leung, N., Lau, K. \& Hang Chung, K. (2008): Impact of First Childbirth on Changes in Women's Preference for Mode of Delivery: Follow-up of a Longitudinal Observational Study. Birth, 35 (2) 121-128.

[35] Serçekuş, P. and Okumus, H. (2009): Fears associated with childbirth among nulliparous women in Turkey. Midwifery, 25 (2) $155-162$. 
[36] Bako, B., Geidam, D., Sanusi, M et al. (2014): Vaginal birth or repeat cesarean section: Women's preferred mode of delivery after a primary cesarean section in Maiduguri, Nigeria. International Journal of Medicine and Medical Sciences. 6 (11): 230-235.
[37] Maryam, Navaee,, Zahra, Abedia (2015): Effect of role play education on primiparous women's fear of natural delivery and their decision on the mode of delivery. Iranian Journal of Nursing and Midwifery Research | January-February | Vol. 20 | Issue 1. pp 45-40. 